\title{
Function-Preserving Neurotized Lateral Arm Free Flap in the Reconstruction of Hemiglossectomy Defects
}

\author{
Divya Prakash¹ T. M. Balakrishnan ${ }^{1, \odot ~ J . ~ J a g a n m o h a n ~}{ }^{1}$ \\ ${ }^{1}$ Department of Plastic, Reconstructive and Faciomaxillary Surgery, \\ Address for correspondence T. M. Balakrishnan, MS, FRCS, DNB, \\ Madras Medical College, Chennai, India \\ Old No 15, New No 10, Thiruvalluvar Street, Rangarajapuram, \\ Kodambakkam, Chennai, Tamil Nadu 600024, India \\ (e-mail: thalaiviri.b@gmail.com).
}

Indian J Plast Surg 2021;54:144-151.

\begin{abstract}
Keywords

- lateral arm flap

- neurotized flap

- posterior antebrachial cutaneous nerve

- fascicular dissection

- hemiglossectomy presented in this article.

\section{Introduction}

Lateral arm free flap (LAFF), since its introduction in 1982, by Song et al, ${ }^{1}$ has been one of the workhorse flap in head and neck, especially tongue, reconstruction owing to its mostly glabrous, thin, and pliable texture. In addition, all the axial vessels of the limb are preserved. However, the donor-site morbidity due to inadvertent injury of posterior antebrachial cutaneous nerve (PABCN) (posterior cutaneous nerve of the forearm) during flap harvest ${ }^{2}$ makes it a second choice only after radial forearm free flap. This significant loss of sensation in the dorsal forearm remains to be a morbidity. Therefore, sparing PABCN at the donor site significantly reduces donor-site morbidity. Considering this, Fogdestam et $\mathrm{al}^{3}$ and Sae Hwi Ki ${ }^{4}$ have attempted in preserving the PABCN.
\end{abstract}

Introduction and Methods The glabrous, thin, and pliable texture of lateral arm flap with no loss of any axial vessel of the limb renders it a good choice for hemiglossectomy defect reconstruction. The main caveat of this flap harvest is the loss of sensation in the distribution of posterior antebrachial cutaneous nerve (PABCN). In this article, we present two strategic sites and techniques to preserve the integrity of PABCN and at the same time harvesting lateral arm flap with a lengthy lower lateral cutaneous nerve of arm for the neurotization. The outcome of this function-preserving neurotized lateral arm free flap in the reconstruction of hemiglossectomy defects is analyzed and

Results Ninety percent of the patients attained grade 3 score in objective assessment, leading to a significant $p$-value of 0.02 with this technique. All had preservation of sensation in the distribution of PABCN.

Conclusion Our technique of harvest and neurotization has brought good functional recovery of the oral cavity with preservation of PABCN.
In both these studies, an attempt to preserve PABCN was done by dividing and reanastomozing, which invariably resulted in temporary anesthesia in the distribution of PABCN which amounts to nonpreservation.

A preliminary cadaver study elicited the feasibility and the safe steps of harvesting the sensate LAFF with preservation of PABCN. These techniques were applied in the clinical study.

\section{Aim \\ A prospective cohort clinical study was conducted to evalu- ate the clinical outcomes of PABCN preserving sensate LAFF harvest and its application in the reconstruction of hemiglos- sectomy defects.}

published online

June 23, 2021
DOI https://doi.org/

10.1055/s-0041-1729507

ISSN 0970-0358 (c) 2021. Association of Plastic Surgeons of India.

This is an open access article published by Thieme under the terms of the Creative Commons Attribution-NonDerivative-NonCommercial-License, permitting copying and reproduction so long as the original work is given appropriate credit. Contents may not be used for commercial purposes, or adapted, remixed, transformed or built upon. (https://creativecommons.org/licenses/by-nc-nd/4.0/).

Thieme Medical and Scientific Publishers Pvt. Ltd. A-12, 2nd Floor, Sector 2, Noida-201301 UP, India 


\section{Materials and Methods}

The conduction of the cadaver and clinical studies were approved by the institutional ethical committee. Written informed consent was obtained from all the patients.

\section{Cadaver Study}

The cadaver study was conducted from January 2014 to January 2015. Twenty-four arms of 12 fresh and preserved adult cadavers ( 6 male and 6 female) were dissected.

After marking the classical lateral arm flap, the posterior skin flap was raised and spiral groove was explored (-Fig. 1).

\section{Key Findings in the Cadaver Study}

Average length of the common stem between PABCN and lower lateral cutaneous nerve of arm (LLCNA) was $2.25 \mathrm{~cm}$. The origin of the common stem was at an average distance of $\sim 3.25 \mathrm{~cm}$ from the lower end of bony spiral groove. No vessels were crossing the common stem posteriorly. The common stem was just distal to the muscular branches of medial head of triceps. The middle collateral branch of radial collateral artery was always found to be anterior to the cutaneous nerves. There was an average of 1.5 neurocutaneous perforators found in the septum between brachialis and the triceps. An average 2.5 of them were septocutaneous perforator from the posterior radial collateral branch. There was one prominent vasa nervorum running on the superior aspect of common stem. The study elicited two strategic locations where the PABCN has to be preserved:

1. At the subcutaneous plane where the PABCN pierced the caudalmost fibers of the lateral head of triceps and coursed parallel and posterior to the lateral intermuscular septum (LIS) of the arm toward the apex of the olecranon (-Fig. 2).

2. In the radial groove. Observing the following anatomical points could ensure the integrity of PABCN within the radial groove:

a. PABCN ran posterior and inferior to LLCNA until both pierced the caudal fibers of the lateral head of triceps with no musculocutaneous or muscle perforator crossing

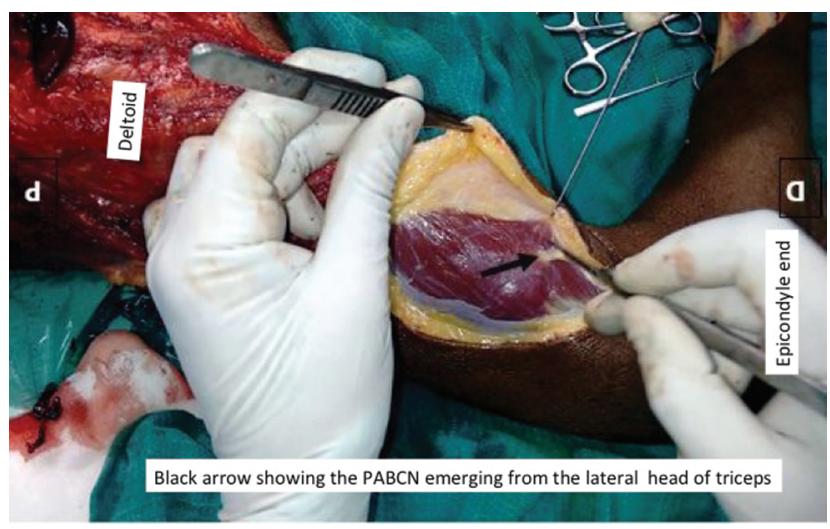

Fig. 1 Dissection in the fresh cadaver shoeing the emergence of PABCN through the lateral head of triceps. posteriorly in its entire course. The course of PABCN in the spiral groove was crossed anteriorly by one cranialmost septofasciocutaneous perforator which could be easily dissected free ( - Fig. 3, - Fig. 4 a,b).

b. PABCN fascicles were located on the inferior aspect of common stem without any interfascicular crossovers.

c. The site of origin of common stem was found distal to the muscular branch to the medial head of triceps and was not crossed superficially by any vessels.

d. Distally in the spiral groove, there was one communicating branch found in 7 out of 24 specimens between the PABCN and LLCNA which could be divided close to the PABCN during the harvest.

\section{Clinical Study and Surgical Technique}

The prospective cohort study was conducted from January 2015 to January 2018. This study included 22 patients ( 6 females and 16 males) with carcinoma of anterolateral tongue who underwent hemiglossectomy and primary reconstruction with function preserving neurotized LAFF (-Table 1).

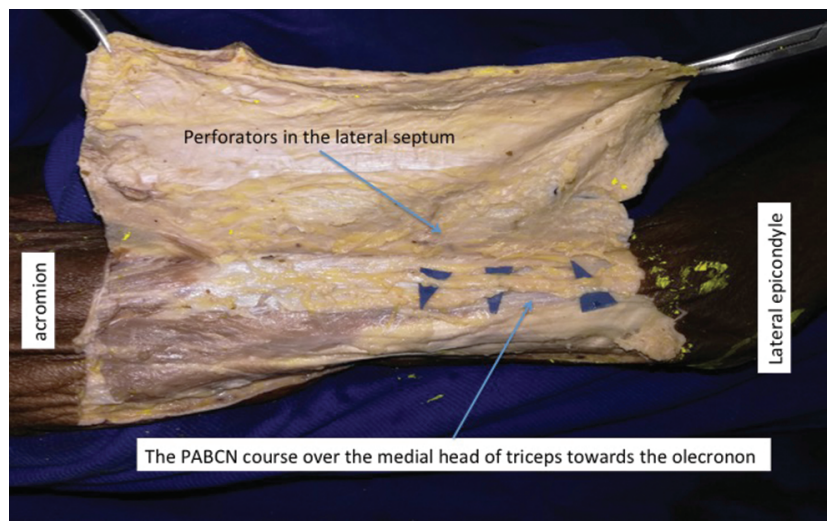

Fig. 2 Dissection in the preserved cadaver showing the preserved PABCN posterior to the lateral intermuscular septum of the arm. (First step of preservation).

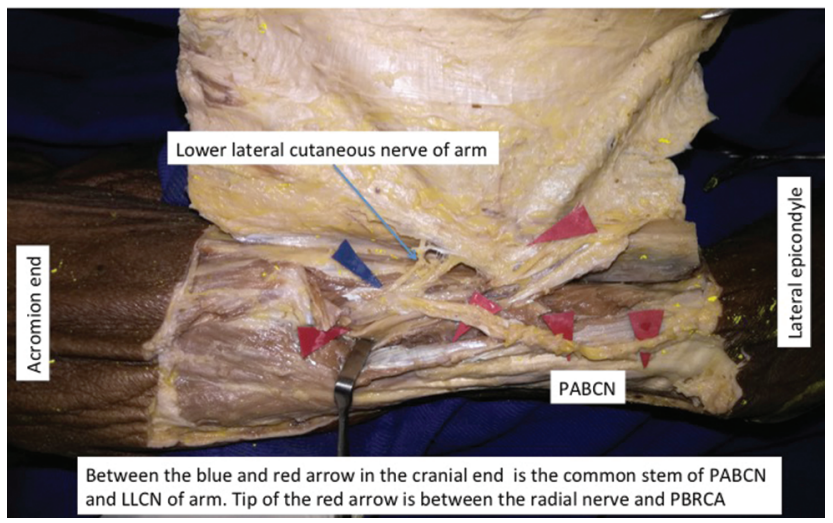

Fig. 3 Cadaveric dissection depicting preservation of PABCN up to the common limb of lower lateral cutaneous nerve of arm and PABCN. The position of common limb of lower lateral cutaneous nerve of arm and $\mathrm{PABCN}$ is shown in the spiral groove. 

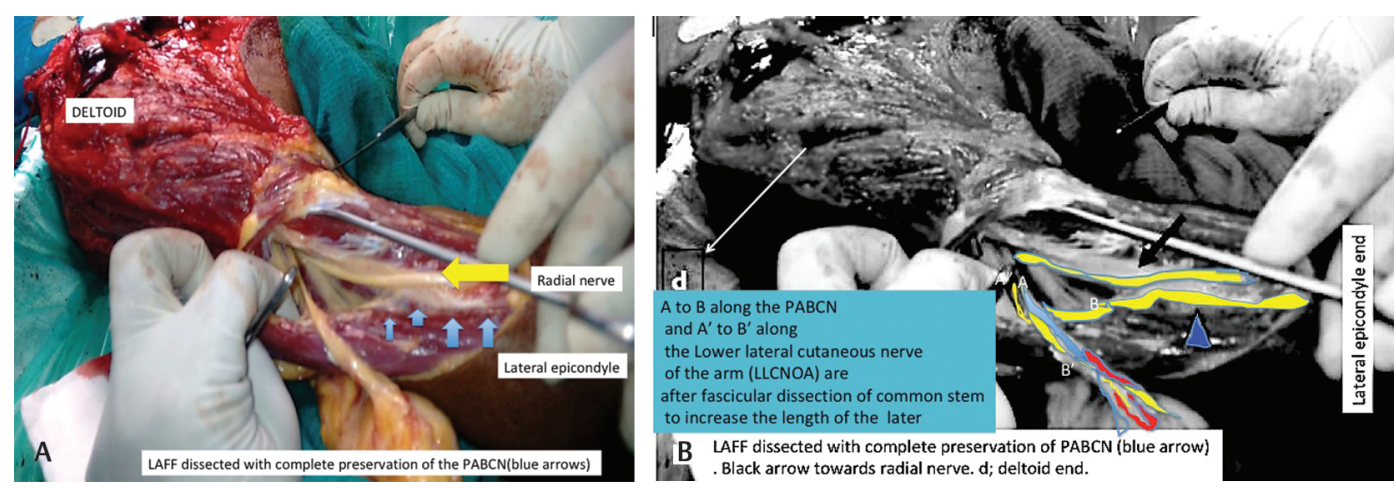

Fig. 4 (A) Dissection in the fresh cadaver showing the harvest of lower lateral cutaneous nerve of arm incorporated LAFF with preservation of PABCN after dissection of the common limb in spiral groove. (B) The line diagram of the picture 5 a to show where the intraneural fascicular dissection is done in the common stem to lengthen the lower lateral cutaneous of arm with preservation of the PABCN.

\section{Selection Criteria}

Patient with stage I, II, and III carcinoma of anterolateral tongue who underwent hemiglossectomy with neck dissection and subsequent reconstruction with the technique described earlier were included.

\section{Exclusion Criteria}

Patients who were unable to follow-up and those with associated severe comorbidities were excluded.

\section{Surgical Technique}

Before surgery, after marking the LIS from deltoid insertion to lateral epicondyle, perforators were marked preoperatively with $10 \mathrm{MHz}$ handheld Doppler. All the flaps were harvested from the nondominant arm. The reconstructive team assessed the post excisional defect after the margins were declared negative. An elliptical flap was marked over the LIS and the dopplered perforators. The posterior nondelineating incision was made and the dissection was performed in the suprafascial plane toward the LIS. In the subcutaneous plane of dissection, PABCN emerging from the caudal fibers of lateral head of triceps, running over the medial head toward anconeus was identified and preserved. PABCN remained subfascial from its origin through the caudal fibers of triceps to $\sim 4.5 \mathrm{~cm}$ proximal to the lateral epicondyle at which point it became subcutaneous. Paying attention to this anatomy during dissection at this level safeguarded PABCN. Further dissection was deepened toward the LIS. All the perforators within the LIS were identified. The point of emergence of LLCNA along with septocutaneous perforators through the caudal fibers of triceps just cranial to PABCN exit was recognized. The anterior incision was completed and the flap elevated in subfascial plane with cephalic vein dissected to an adequate length extending from the cranial end of the flap. The LIS with periperforator dissection was performed through the medial head obliquely into the spiral groove. The course of PABCN and LLCNA were also identified posterior to the vasculature in the spiral groove. At the distal end of spiral groove anterior branch of radial collateral artery was ligated. The perforators were followed to the PBRCA and in turn well proximally up to two-thirds of the spiral groove where adequate-sized vessels with venae commitantes were found anterior and superior to the radial nerve. Fascicular dissection was done to get adequate length of LLCNA ( - Fig. $\mathbf{5}$, -Fig. 6, - Fig. 7). In only four clinical cases, the adequate length was available because of high origin and very short common stem. The nerve was divided at its confluence. The safe technique to harvest sensate LAFF with lengthy neurovascular pedicle with preservation of $\mathrm{PABCN}$ was to perform retrograde dissection. All the perforators with overlying skin paddle were dissected and perfect hemostasis ensured. Recipient vessels and lingual nerve stump were prepared while the flap was getting perfused in situ. In cases of marginal mandibulectomy, the breadth of the skin paddle ellipse was increased to accommodate the floor of mouth defect across the mandible to gingivobuccal sulcus. Then the flap was transferred, folded, and given inset to reform the tongue morphology, ensuring the mobility of tongue with pedicle exiting from the posterior aspect. The vessels and nerves were anastomosed in a tensionless manner. Layered closure was done with a Segmular drain. All the secondary defects were closed primarily.

\section{Assessment}

All the patients were assessed on day 3 for any paresthesia or dysesthesia in the PABCN distribution. Patients were followed-up at three monthly intervals up to 24 months. Two-point discrimination (2PD) was measured at the reconstructed portion of the tongue and the dorsum of forearm with static discriminator. The extent of tongue movements and linguodental and linguopalatal pronunciations were assessed. All the patients were subjectively assessed using modified University of Washington quality of life (MUW-QOL) $)^{5}$ questionnaire score $(-$ Fig. 8). At the end of average follow-up period, all the patients were assessed by two individual observers based on institutional postglossectomy assessment score ( $\boldsymbol{- \text { Fig. 9) }}$ ) and the final score was calculated for each patient ( - Table $\mathbf{1}$ ).

\section{Results}

The average age of the patients in our study was 55 years. Sixteen patients were male and 6 were female ( - Table $\mathbf{1}$ ). 
Table 1 Patient details

\begin{tabular}{|c|c|c|c|c|c|c|c|c|}
\hline S. No. & $\begin{array}{l}\text { Patient } \\
\text { age/ } \\
\text { sex }\end{array}$ & Procedure done & $\begin{array}{l}\text { Recipient } \\
\text { vessels }\end{array}$ & $\begin{array}{l}\text { Size of } \\
\text { flap } \\
(\mathrm{cm})\end{array}$ & Complication & $\begin{array}{l}\text { Follow-up } \\
\text { period } \\
\text { in months }\end{array}$ & $\begin{array}{l}\text { Subjective } \\
\text { grade }\end{array}$ & $\begin{array}{l}\text { Objective } \\
\text { assess- } \\
\text { ment score }\end{array}$ \\
\hline 1 & $40 / \mathrm{M}$ & $\begin{array}{l}\text { Hemiglossectomy, } \\
\text { SOHD, and marginal } \\
\text { mandibulectomy }\end{array}$ & $\begin{array}{l}\text { Facial artery } \\
\text { and IJV (ES) }\end{array}$ & $6 \times 5.5$ & Nil & 16 & A & 3 \\
\hline 2 & $53 / \mathrm{M}$ & $\begin{array}{l}\text { Hemiglossectomy and } \\
\text { MRND } 2\end{array}$ & $\begin{array}{l}\text { Facial artery } \\
\text { and vein }\end{array}$ & $5.5 \times 4.5$ & Nil & 18 & A & 3 \\
\hline 3 & $39 / \mathrm{F}$ & $\begin{array}{l}\text { Hemiglossectomy and } \\
\text { MRND } 2\end{array}$ & $\begin{array}{l}\text { STA and } \\
\text { LFVT } \\
\end{array}$ & $4 \times 3$ & Nil & 12 & A & 3 \\
\hline 4 & $35 / \mathrm{M}$ & $\begin{array}{l}\text { Hemiglossectomy, } \\
\text { SOHD, and marginal } \\
\text { mandibulectomy }\end{array}$ & STA and EJV & $4.5 \times 3.5$ & $\begin{array}{l}\text { Paraesthesia over PABCN } \\
\text { territory for } 14 \text { days } \\
\text {.Venous thrombosis-flap } \\
\text { salvaged. }\end{array}$ & 16 & A & 3 \\
\hline 5 & $60 / \mathrm{M}$ & $\begin{array}{l}\text { Hemiglossectomy, } \\
\text { MRND, and marginal } \\
\text { mandibulectomy }\end{array}$ & $\begin{array}{l}\text { STA and } \\
\text { LFVT }\end{array}$ & $4 \times 3$ & Nil & 18 & A & 2 \\
\hline 6 & $57 / F$ & $\begin{array}{l}\text { Hemiglossectomy and } \\
\text { MRND } 2\end{array}$ & STA and EJV & $6.5 \times 4.5$ & Nil & 10 & A & 3 \\
\hline 7 & $52 / \mathrm{M}$ & $\begin{array}{l}\text { Hemiglossectomy and } \\
\text { SOHD }\end{array}$ & $\begin{array}{l}\text { Facial artery } \\
\text { and vein }\end{array}$ & $6 \times 4.5$ & Nil & 24 & A & 3 \\
\hline 8 & $62 / M$ & $\begin{array}{l}\text { Hemiglossectomy and } \\
\text { MRND }\end{array}$ & $\begin{array}{l}\text { STA and } \\
\text { LFVT } \\
\end{array}$ & $5.5 \times 4$ & Nil & 12 & A & 3 \\
\hline 9 & $49 / \mathrm{M}$ & $\begin{array}{l}\text { Hemiglossectomy and } \\
\text { MRND }\end{array}$ & $\begin{array}{l}\text { STA and } \\
\text { LFVT }\end{array}$ & $6.5 \times 4.5$ & $\begin{array}{l}\text { Hypertrophic scar in the } \\
\text { donor site }\end{array}$ & 24 & A & 3 \\
\hline 10 & $65 / F$ & $\begin{array}{l}\text { Hemiglossectomy and } \\
\text { SOHD }\end{array}$ & $\begin{array}{l}\text { STA and } \\
\text { LFVT }\end{array}$ & $5.5 \times 4.5$ & nil & 18 & A & 3 \\
\hline 11 & $53 / \mathrm{F}$ & $\begin{array}{l}\text { Hemiglossectomy and } \\
\text { MRND }\end{array}$ & $\begin{array}{l}\text { STA and } \\
\text { LFVT }\end{array}$ & $4.5 \times 3$ & $\begin{array}{l}\text { Hypertrophic scar at the } \\
\text { donor site }\end{array}$ & 16 & $B$ & 2 \\
\hline 12 & $46 / \mathrm{M}$ & $\begin{array}{l}\text { Hemiglossectomy. } \\
\text { MRND, and marginal } \\
\text { mandibulectomy }\end{array}$ & STA and EJV & $4 \times 3.5$ & Nil & 24 & A & 3 \\
\hline 13 & $58 / \mathrm{M}$ & $\begin{array}{l}\text { Hemiglossectomy and } \\
\text { MRND }\end{array}$ & STA and EJV & $4.5 \times 4$ & Nil & 24 & A & 3 \\
\hline 14 & $69 / M$ & $\begin{array}{l}\text { Hemiglossectomy and } \\
\text { MRND } 2\end{array}$ & $\begin{array}{l}\text { Facial } \\
\text { vessels }\end{array}$ & $5.5 \times 3.5$ & Nil & 12 & A & 2 \\
\hline 15 & $55 / M$ & $\begin{array}{l}\text { Hemiglossectomy and } \\
\text { SOHD }\end{array}$ & $\begin{array}{l}\text { Facial } \\
\text { vessels }\end{array}$ & $4.5 \times 3$ & Nil & 14 & A & 3 \\
\hline 16 & $63 / M$ & $\begin{array}{l}\text { Hemiglossectomy, } \\
\text { MRND, and marginal } \\
\text { mandibulectomy }\end{array}$ & STA and EJV & $6.5 \times 4.5$ & Nil & 16 & A & 2 \\
\hline 17 & $67 / M$ & $\begin{array}{l}\text { Hemiglossectomy and } \\
\text { SOHD }\end{array}$ & $\begin{array}{l}\text { STA and IJV } \\
\text { (ES) }\end{array}$ & $4 \times 3.5$ & Nil & 12 & A & 3 \\
\hline 18 & $54 / F$ & $\begin{array}{l}\text { Hemiglossectomy and } \\
\text { MRND }\end{array}$ & STA & $5.5 \times 4$ & $\begin{array}{l}\text { Paraesthesia over PABCN } \\
\text { for } 12 \text { days }\end{array}$ & 24 & A & 3 \\
\hline 19 & $47 / \mathrm{M}$ & $\begin{array}{l}\text { Hemiglossectomy and } \\
\text { MRND }\end{array}$ & $\begin{array}{l}\text { STA and } \\
\text { LFVT }\end{array}$ & $5 \times 4.5$ & Nil & 12 & A & 3 \\
\hline 20 & $54 / \mathrm{M}$ & $\begin{array}{l}\text { Hemiglossectomy and } \\
\text { SOHD }\end{array}$ & $\begin{array}{l}\text { Facial } \\
\text { vessels }\end{array}$ & $4 \times 3.5$ & Nil & 24 & A & 3 \\
\hline 21 & $68 / \mathrm{F}$ & $\begin{array}{l}\text { Hemiglossectomy and } \\
\text { SOHD }\end{array}$ & $\begin{array}{l}\text { STA and } \\
\text { LFVT }\end{array}$ & $4.5 \times 4$ & Nil & 24 & B & 3 \\
\hline 22 & $71 / \mathrm{M}$ & $\begin{array}{l}\text { Hemiglossectomy and } \\
\text { MRND }\end{array}$ & STA and EJV & $4 \times 4.5$ & Nil & 16 & A & 3 \\
\hline
\end{tabular}

Abbreviations: F, female; IJV, internal jugular vein; LFVT, linguofacial venous trunk; M, male; MRND, modified radical neck dissection; PABCN, posterior antebrachial cutaneous nerve; STA, superior thyroid artery; SOHD, supraomohyoid neck dissection.

All of them had a history of tobacco usage preoperatively. Adjuvant radiotherapy was administered postoperatively to all the patients and they were followed-up for an average of 17.3 months. Minimum follow-up period was 10 months $(n=1)$. The average size of flap harvested was $5 \times 5.2 \mathrm{~cm}$. One patient developed hypertrophic donor scar at 12 months and another had a stretched and widened scar. Two patients had temporary paresthesia in the PABCN distribution for 2 weeks 


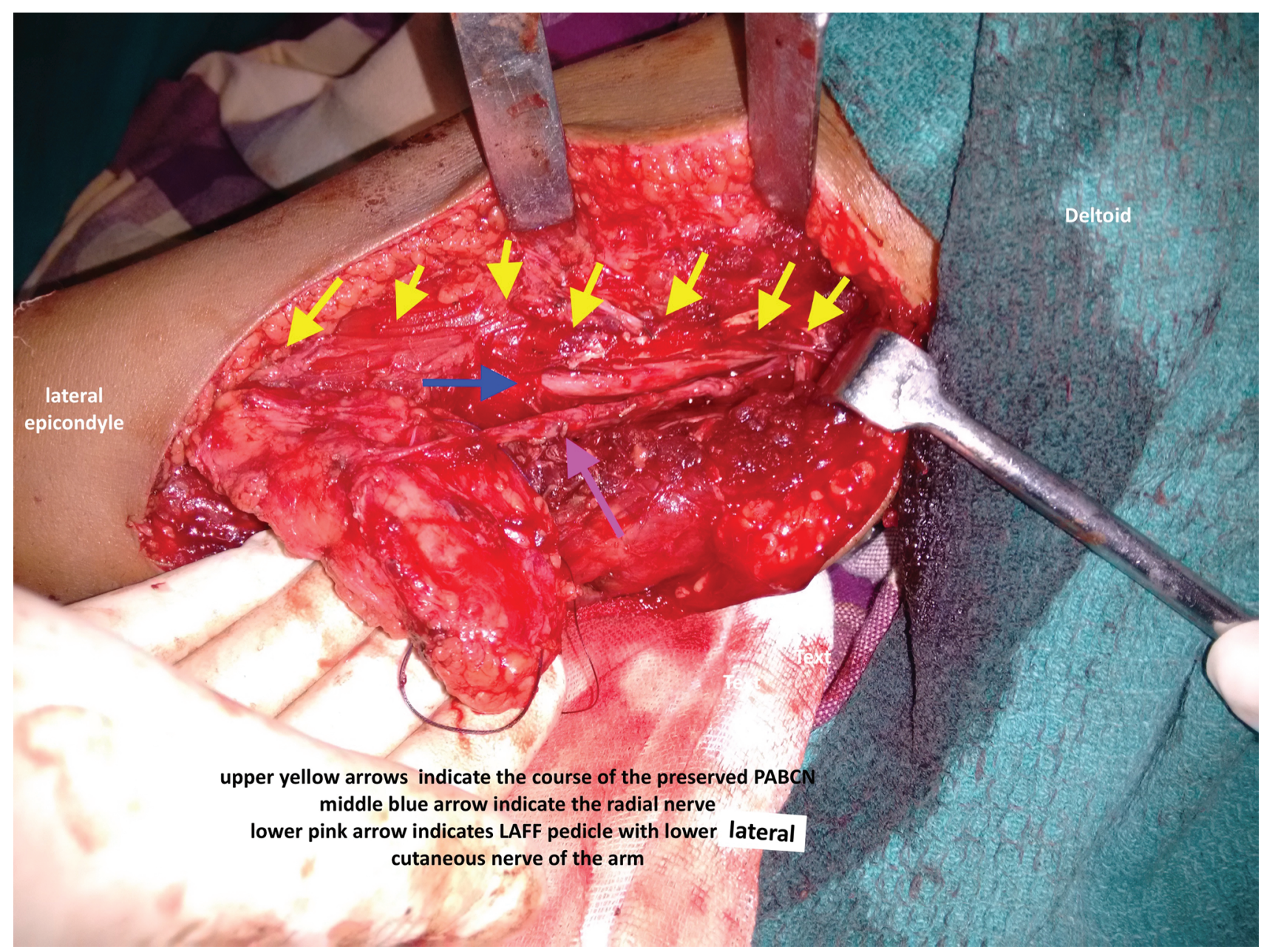

Fig. 5 Intraoperative image showing the preserved PABCN (yellow arrows) exiting from the radial nerve (blue arrow) and the increased length of lower lateral cutaneous nerve of arm after intrafascicular dissection with the LAFF (pink arrow).

and it resolved spontaneously to S4 sensation. None developed loss of sensation in the PABCN cutaneous distribution. The average length of LLCNA gained with intraneural fascicular dissection of the common stem in the spiral groove was $2.75 \mathrm{~cm}$. Only one patient had venous thrombosis but the flap was salvaged by exploration and redo vein anastomosis.

Ninety percent of the patients attained a static 2PD ranging from 10 to $15 \mathrm{~mm}$ in the reconstructed tongue at an average period of 8.5 months. Comprehensible linguodental and linguopalatal pronunciations were achieved by $85 \%$ of the patients at the mean of 9 months. All the patients had a swallowing score of 3 by an average of 9.5 months. None developed swallowing difficulty or locoregional or distant metastasis within the follow-up period. Ninety percent of the patients attained grade 3 score in objective assessment $(p=0.02)$.

Twenty out of 22 patients (90\%) achieved subjective good to excellent grade "A" score, expressing their gratification in the quality of postreconstruction life assessed using MUW-QOL score $(p=0.006)$. The remaining two patients got a fair score expressing mild dissatisfaction about the quality of speech.

\section{Discussion}

The tongue plays a crucial role in the mastication, oropharyngeal phase of swallowing, and speech. To serve all these important functions the tongue has been endowed with a large representation in the sensory and motor homunculus of the dominant cortical brain. ${ }^{6}$ Although there is no concrete evidence in the present literature supporting the sensate flap, it may appear logical to reconstruct the hemiglossectomy defects with a sensate flap. ${ }^{7}$ This purpose is served well by the sensate LAFF. But the harvest of sensate LAFF is undermined by the loss of sensation in the PABCN distribution. To the best of our knowledge, in the available literature, no lucid steps are described for the preservation of the PABCN. $3,4,8$

Our study aims at simultaneous preservation of PABCN at the donor site and to get a lengthy LLCNA facilitating tension-free anastomosis. In this study, we have paid attention to two different sites for dissecting and safeguarding PABCN-the spiral groove and the subcutaneous plane over the medial head of triceps. Careful fascicular dissection preserved PABCN and also rendered a good length of LLCNA. 


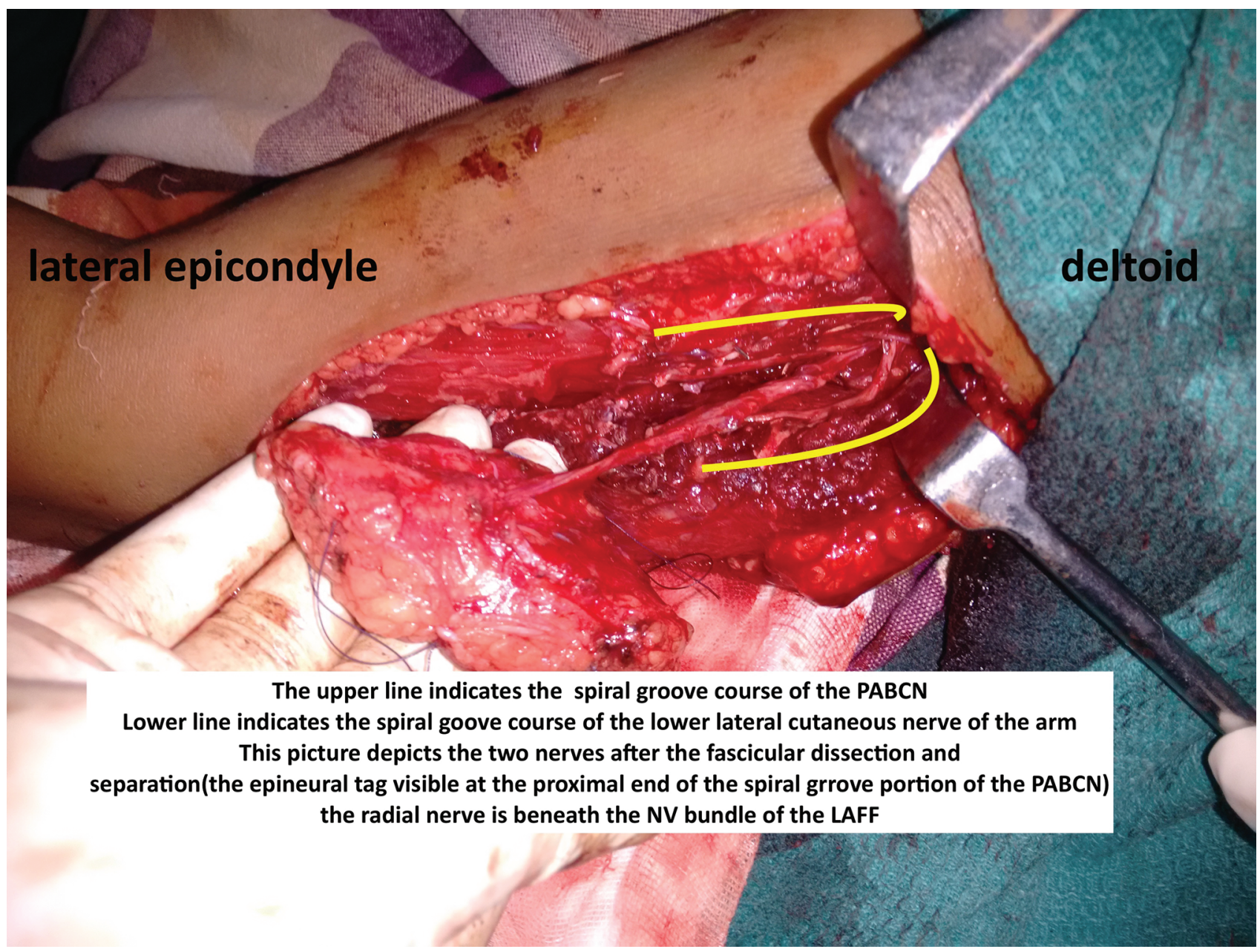

Fig. 6 Intraoperative image showing the two nerves: Upper yellow line indicating PABCN and lower yellow line indicating lower lateral cutaneous nerve, after fascicular dissection and separation. Radial nerve is seen below the pedicle of LAFF.

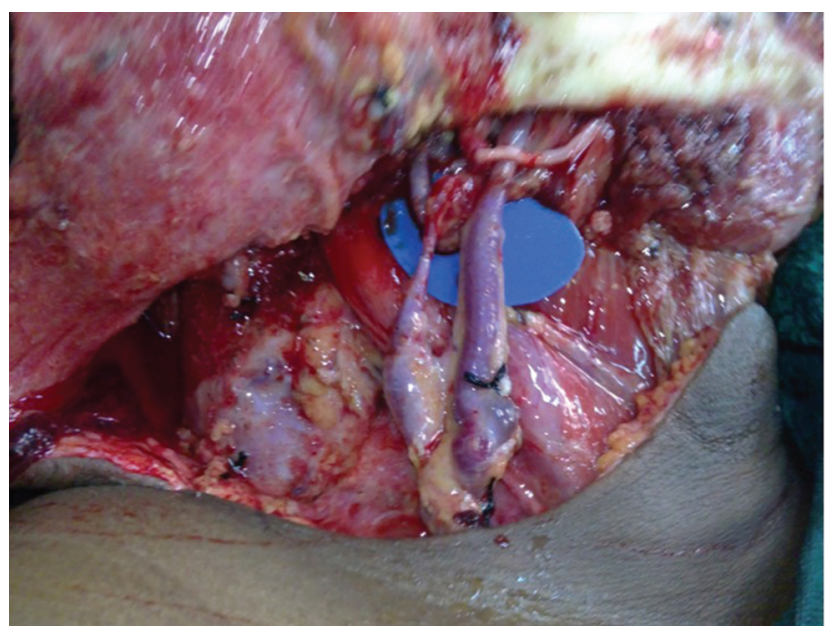

Fig. 7 Close up view of tensionless coaptation of lower lateral cutaneous nerve of arm to lingual nerve.

Good to excellent post reconstruction functional recovery in our study may be attributed to the following:

- Harvest of LLCNA with intact vasa nervorum.

- Preservation of all neurocutaneous perforators during the harvest.
- Tensionless coaptation with the fascicular dissected lengthy stump of LLCNA facilitating the anastomosis to lingual nerve proximal to the lingual groove of the mandible.

- The recovered general visceral afferent (haptic feedback) sensation in the reconstructed tongue reinforced the functional recovery of residual tongue.

LAFF has several advantages over radial forearm flap. ${ }^{9-13}$ Most important being the expendable vascularity. The glabrous moderately thick flap with the prospectus for neurotization and the ease of harvest without the need of change in position makes it a flap of choice in head and neck reconstruction. ${ }^{8,14-32}$ The donor site can be closed primarily and the scar, being hidden in clothing, is aesthetically acceptable. Moderate subcutaneous arm tissue provides bulk to obliterate the hemiglossectomy defects. ${ }^{8}$ In addition to that, safe steps for the preservation of PABCN exonerates the sensate LAFF from its long-standing curse of causing anesthesia in the contact surface of the forearm.

Faria et a ${ }^{29}$ in 2008 reported their study of 210 patients who underwent LAFF for head and neck defects that included 53 cases of glossectomy defects ranging from hemi-, total, and extended glossectomy. Paraesthesia of forearm was reported to be the main donor-site complication in $100 \%$ of 
Modified University of Washington Quality of Life Questionnaire (MUW-QOL)

1. Pain. (Check one box: $\square$ )

I have severe pain, not controlled by medication.

I have moderate pain - requires regular medication

There is mild pain not needing medication.

I have no pain.

2. The appearance of tongue (Check one box: $\square$ )

$\square \quad$ I cannot be with people due to my appearance.

$\square \quad$ My appearance bothers me but I remain active.

$\square \quad$ The change in appearance of tongue is minor.

$\square$ There is no change in the appearance of my tongue.

3. Function of the upper limb. (Check one box: $\square$ )

I Cannot work due to problems with my elbow.

Pain or weakness in my elbow has caused me to change my work

I cannot work when my elbow is extended otherwise I am normal

I have no problem with my arm

4. Swallowing. (Check one box: $\square$ )

$\square$ I cannot swallow because it "goes down the wrong way" and chokes me

I can only swallow liquid food.

I cannot swallow certain solid foods

I can swallow as well as ever.

5. Chewing. (Check one box: $\square$ )

I cannot even chew soft solids

Despite my efforts, food stays in the mouth

I can eat soft solids but cannot chew some.

I can chew as well as ever

6. Speech. (Check one box: $\square$ )

$\square \quad$ I cannot be understood.

Only my family and friends can understand me

I have difficulty saying some words

My speech is the same as always

7. Feel over the back of forearm (Check one box: $\square$ )

$\square \quad$ I am not able to feel anything so that am not able to use my hand

$\square \quad$ I am feeling a tingling sensation and deep pain in the forearm

$\square$ I feel numb but my activities are not affected by the numbness

$\square$ I have no change in the sensation of my forearm

TOTAL SCORE : $\square / 28$

Subjective grade:

$\square$ 21-28 - Good to Excellent - A grade

$\square$ 15-20 - Fair - B grade

$\leq 15$ - poor $\quad-\mathrm{C}$ grade

Fig. 8 Modified University of Washington questionnaire (UWQOL) used for the subjective assessment of tongue reconstruction.

\section{COMPREHENSIVE POSTOPERATIVE ASSESSMENT SCORE}

\begin{tabular}{|l|l|}
\hline Score & Criteria \\
\hline 1 Poor & $\begin{array}{l}\text { - Incomprehensible linguodental and linguopalatal } \\
\text { pronunciations /potato in mouth or wet speech }\end{array}$ \\
& $\begin{array}{l}\text { - Some tongue mobility present but swallowing and } \\
\text { mastication involves preferentially the non- } \\
\text { operated side }\end{array}$ \\
\hline - $2 \mathrm{PD}$ - absent
\end{tabular}

Fig. 9 Institutional comprehensive postoperative assessment objective scoring system.

the patients. Also, the nonneurotized flaps used in 53 tongue defects were shown to have poor to moderate sensory recovery. Graham et al in $1992^{2}$ has reported his observations on complications and morbidity in donor and recipient sites of 123 LAFF. About 59\% of his patients complained of numbness over the forearm that remained unchanged in the follow-up period. Sixteen out of 44 cases reported by Gellrich et $\mathrm{al}^{26}$ were hemiglossectomy defects reconstructed with LAFF. They reported a $61.4 \%$ sensory disturbance over the dorsal forearm as the most common donor-site complication.

Functional assessment of the reconstructed tongue has been studied and reported by a few studies. Gellrich et $\mathrm{al}^{26}$ analyzed the swallowing function after reconstruction with LAFF using videoflurography and reported that there was no complete functional restoration despite good morphological restoration. Hara et $\mathrm{al}^{30}$ compared swallowing and speech function in 25 patients, 17 patients reconstructed with LAFF, and 7 with RFFF. None of the flaps were neurotized. They inferred that the quality of functions did not differ with the type of flap. In this study, most of the patients have reported dissatisfaction with tongue movements, speech, and swallowing. However, Hara et al have concluded the study recommending LAFF to be their first choice for tongue reconstruction due to less donor-site morbidity compared with RFFF. In a retrospective study of 48 LAFF for tongue defects done by Thankappan et $a l,{ }^{8}$ morbidity and functional and aesthetic outcomes were analyzed in 37 patients for 6 months. Here again, sensory disturbance over forearm was found to be a disturbing donor-site morbidity. Fifty-four percent and $58 \%$ of patients had normal to near-normal speech and tongue movements, respectively. Xerostomia caused by adjuvant radiotherapy was considered to be the significant cause of restricted mobility in the remaining patients. None of the flaps used for hemiglossectomy defects were neurotized in this study. Though the author has noted radiotherapy-induced temporary xerostomia with mild mucositis in $~ 70 \%$ of cases in this study, none of them had any effect on the nerve healing, thus facilitating the good to excellent functional outcome. ${ }^{33,34}$

The strength of our study is the cadaver dissection establishing the safe technique of harvesting LLCNA without injuring PABCN. The clinical study established a useful adaptation of this technique for the better functional outcome of the oral cavity. Since the limitation of this study is its small size, a larger-scale study is required to establish the superiority of this function-preserving technique to harvest a sensate LAFF for the fast functional recovery of the finest organ of oral cavity, the tongue.

\section{Conclusion}

Our technique of complete preservation of PABCN would add to the advantage of LAFF for being considered the workhorse flap in the reconstruction of medium-size tongue defects with no donor-site morbidity. This may also have facilitated functional recovery. This study provided the definitive steps in the dissection and preservation of PABCN which has eschewed the long-spoken drawback of sensate LAFF. Our technique of harvesting sensate LAFF with lengthy LLCNA has a prospectus for early functional recovery of the oral cavity reconstructions. 


\section{Financial Support Declaration}

None.

\section{Conflict of Interests}

None declared.

\section{References}

1 Song R, Song Y, Yu Y, Song Y. The upper arm free flap. Clin Plast Surg 1982;9(1):27-35

2 Graham B, Adkins P, Scheker LR. Complications and morbidity of the donor and recipient sites in 123 lateral arm flaps. J Hand Surg [Br] 1992;17(2):189-192

3 Fogdestam I, Tarnow P, Kalaaji A. Extended free lateral arm flap with preservation of the posterior cutaneous nerve of the forearm. Scand J Plast Reconstr Surg Hand Surg 1996;30(1):49-55

$4 \mathrm{Ki} \mathrm{SH}$. Lateral arm free flap with preservation of the posterior antebrachial cutaneous nerve. Ann Plast Surg 2016;76(5):517-520

$5 \mathrm{Ho} \mathrm{JH}$, University of Washington quality of life questionnaire. In: Michalos AC, ed. Encyclopaedia of Quality of Life and Well-Being Research., Dordrecht, Netherlands Springer 2014

6 Boyd B, Mulholland S, Gullane P, et al. Reinnervated lateral antebrachial cutaneous neurosome flaps in oral reconstruction: are we making sense? Plast Reconstr Surg 1994;93(7):1350-1359, discussion 1360-1362

7 Namin AW, Varvares MA. Functional outcomes of sensate versus insensate free flap reconstruction in oral and oropharyngeal reconstruction: a systematic review. Head Neck 2016;38(11):1717-1721

8 Thankappan K, Kuriakose MA, Chatni SS, et al. Lateral arm free flap for oral tongue reconstruction: an analysis of surgical details, morbidity, and functional and aesthetic outcome. Ann Plast Surg 2011;66(3):261-266

9 Brown JS, Rogers SN, Lowe D. A comparison of tongue and soft palate squamous cell carcinoma treated by primary surgery in terms of survival and quality of life outcomes. Int J Oral Maxillofac Surg 2006;35(3):208-214

10 Shpitzer T, Guttman D, Gur E, Feinmesser R, Ad-El D. Transoral reconstruction of the mobile tongue, using radial forearm free flap. Microsurgery 2003;23(1):18-20

11 Hsiao HT, Leu YS, Lin CC. Tongue reconstruction with free radial forearm flap after hemiglossectomy: a functional assessment. J Reconstr Microsurg 2003;19(3):137-142

12 Kuriakose MA, Loree TR, Spies A, Meyers S, Hicks WL Jr. Sensate radial forearm free flaps in tongue reconstruction. Arch Otolaryngol Head Neck Surg 2001;127(12):1463-1466

13 Richardson D, Fisher SE, Vaughan ED, Brown JS. Radial forearm flap donor-site complications and morbidity: a prospective study. Plast Reconstr Surg 1997;99(1):109-115

14 Katsaros J, Schusterman M, Beppu M. Banis JC Jr, Acland RD. The lateral upper arm flap: anatomy and clinical applications. Ann Plast Surg 1984;12(6):489-500

15 Matloub HS, et al. The lateral arm flap. A neurosensory free flap. In: Williams HB, ed. Transactions of the VIII International Congress of Plastic Surgery. Montreal, Canada: IPRS;1983:125

16 Nahabedian MY, Deune EG, Manson PN. Utility of the lateral arm flap in head and neck reconstruction. Ann Plast Surg 2001;46(5):501-505
17 Wax MK, Briant TD, Mahoney JL. Lateral-arm free flap for reconstruction in the head and neck. J Otolaryngol 1996;25(3):140-144

18 Wenig BL. The lateral arm free flap for head and neck reconstruction. Otolaryngol Head Neck Surg 1993;109(1):116-119

19 Sullivan MJ, Carroll WR, Kuriloff DB. Lateral arm free flap in head and neck reconstruction. Arch Otolaryngol Head Neck Surg 1992;118(10):1095-1101

20 Akinci M, Ay S, Kamiloglu S, Erçetin O. Lateral arm free flaps in the defects of the upper extremity-a review of 72 cases. Hand Surg 2005;10(2-3):177-185

21 Ulusal BG, Lin YT, Ulusal AE, Lin $\mathrm{CH}$. Free lateral arm flap for 1-stage reconstruction of soft tissue and composite defects of the hand: A retrospective analysis of 118 cases. Ann Plast Surg 2007;58(2):173-178

22 Kim CH, Tark MS, Choi CY, Kang SG, Kim YB. A single-stage reconstruction of a complex Achilles wound with modified free composite lateral arm flap. J Reconstr Microsurg 2008;24(2):127-130

23 Haas F, Seibert FJ, Koch H, et al. Reconstruction of combined defects of the Achilles tendon and the overlying soft tissue with a fascia lata graft and a free fasciocutaneous lateral arm flap. Ann Plast Surg 2003;51(4):376-382

24 Song XM, Yuan Y, Tao ZJ, Wu HM, Yuan H, Wu YN. Application of lateral arm free flap in oral and maxillofacial reconstruction following tumor surgery. Med Princ Pract 2007;16(5):394-398

25 Kokkalis ZT, Papanikos E, Mazis GA, Panagopoulos A, Konofaos P. Lateral arm flap: indications and techniques. Eur J Orthop Surg Traumatol 2019;29(2):279-284

26 Gellrich NC, Schramm A, Hara I, Gutwald R, Düker J, Schmelzeisen R. Versatility and donor site morbidity of the lateral upper arm flap in intraoral reconstruction. Otolaryngol Head Neck Surg 2001;124(5):549-555

27 Alcalde Navarrete J, Pastor MJ, Quesada JL, et al . Reconstruction of oropharyngeal defects with lateral arm flap [in Spanish] Acta Otorrinolaringol Esp 2001;52(1):39-44

28 Lanzetta M, Bernier M, Chollet A, St-Laurent JY. The lateral forearm flap: an anatomic study. Plast Reconstr Surg 1997;99(2):460-464

29 Marques Faria JC, Rodrigues ML, Scopel GP, Kowalski LP, Ferreira MC. The versatility of the free lateral arm flap in head and neck soft tissue reconstruction: clinical experience of 210 cases. J Plast Reconstr Aesthet Surg 2008;61(2):172-179

30 Hara I, Gellrich NC, Duker J, et al. Swallowing and speech function after intraoral soft tissue reconstruction with lateral upper arm free flap and radial forearm free flap. Br J Oral Maxillofac Surg 2003;41(3):161-169

31 Civantos FJ Jr, Burkey B, Lu FL, Armstrong W. Lateral arm microvascular flap in head and neck reconstruction. Arch Otolaryngol Head Neck Surg 1997;123(8):830-836

32 Reinert S. The free revascularized lateral upper arm flap in maxillofacial reconstruction following ablative tumour surgery. J Craniomaxillofac Surg 2000;28(2):69-73

33 Balakrishnan TM, Jayachandiran AP, Hariraj DD, Jaganmohan J. Chimeric anterolateral thigh flap for primary functional reconstruction of complex, composite near total hemi facial post excision defects. J Craniofac Surg 2020;31(4):e337-e343

34 Pauloski BR, Rademaker AW, Logemann JA, Colangelo LA. Speech and swallowing in irradiated and nonirradiated postsurgical oral cancer patients. Otolaryngol Head Neck Surg 1998;118(5):616-624 